\title{
Evidence for impacts by jellyfish on North Sea herring recruitment
}

\author{
Christopher P. Lynam ${ }^{1, *}$, Michael R. Heath ${ }^{2}$, Stephen J. Hay ${ }^{2}$, Andrew S. Brierley ${ }^{1}$ \\ ${ }^{1}$ Gatty Marine Laboratory, University of St. Andrews, Fife KY16 8LB, UK \\ ${ }^{2}$ Marine Laboratory, PO Box 101, Victoria Road, Aberdeen AB11 9DB, UK
}

\begin{abstract}
Jellyfish (Scyphozoa) prey on and consume many of the same food items as do larvae of herring Clupea harengus and could therefore have a detrimental impact on larval survival. A reduction in the spawning stock biomass of herring may release jellyfish from competition for prey with herring and exacerbate any impact by jellyfish on herring survival. Both jellyfish abundance and the spawning success of herring fluctuate from year to year and increase under similar environmental conditions. The abundance of medusae (diameter $=1$ to $47 \mathrm{~cm}$, June to August) at herring spawning areas in the North Sea was correlated positively with the abundance of recently hatched herring larvae $(<1 \mathrm{~cm}$, sampled 1 to 15 September 1971 to 1986), and this concurrence heightens the potential for competition. A significant negative relationship $(\mathrm{p}<0.05)$ between the survival of herring to Age 0 and the abundance of the scyphozoan Aurelia aurita implies that this jellyfish might adversely impact the North Sea herring population. Furthermore, regression analyses suggest that climate variability may mediate the possible impact by $A$. aurita on herring survival and 0 -group recruitment through changes in the North Atlantic Oscillation Index and the abundance of the scyphozoan Cyanea capillata $\left(\mathrm{r}^{2}>0.60, \mathrm{p}<0.05\right)$. Management of North Sea herring may benefit from the inclusion of predation and competition effects of medusae into forecasting models of herring recruitment.
\end{abstract}

KEY WORDS: Jellyfish · Medusae $\cdot$ Herring $\cdot$ Larval survival $\cdot$ Recruitment $\cdot$ North Atlantic Oscillation

Resale or republication not permitted without written consent of the publisher

\section{INTRODUCTION}

Jellyfish (medusae of Scyphozoa) abundance is increasing in many marine ecosystems (Mills 2001, Xian et al. 2005) and, because jellyfish are important consumers of zooplankton, they might have an increasingly adverse affect on fish populations (Schneider \& Behrends 1998, Purcell \& Arai 2001, Sommer et al. 2002). Aurelia aurita has had devastating impacts on Atlantic herring larvae (Clupea harengus) in a Baltic Sea fjord (Möller 1984), and Aequorea victoria is a major cause of mortality of Pacific herring larvae (C. pallasi) in Kulleet Bay, British Columbia (Purcell \& Grover 1990). Möller (1984) reported that even a small A. aurita ephyra (diameter $=6 \mathrm{~mm}$ ) was able to catch Atlantic herring larvae, and Möller also found 68 larvae in the stomach of a single medusa only $42 \mathrm{~mm}$ in diameter. Competition for food between jellyfish and adult finfish has also been shown, with dietary similarities of 73 and $50 \%$ respectively for Pacific herring and medusae of Aurelia labiata and Cyanea capillata (Purcell \& Sturdevant 2001)

In the North Sea, the abundance of the jellyfish Aurelia aurita, Cyanea lamarckii and C. capillata fluctuated substantially between 1971 and 1986 (Hay et al. 1990). At a regional level, part of the interannual variability has been linked to changes in the climate as quantified by the North Atlantic Oscillation Index (NAOI). The abundance of medusae was generally high east of Scotland and west of Denmark when the NAOI was low (Lynam et al. 2004). Similarly, a low NAO phase has been associated with beneficial conditions for Bohuslän herring in the Skagerrak (Alheit \& Hagen 1997). Conversely, a high NAO phase appears 
to result in more favourable conditions for jellyfish north of Scotland, an area subject to a greater oceanic influence (Lynam et al. 2005), and for spring-spawning herring in the English Channel (Alheit \& Hagen 1997). So, both the abundance of medusae and herring, and their distributions, appear to be linked to climatic variation.

The distributions of jellyfish and herring in the North Sea overlap spatially and temporally, so the possibility exists that jellyfish impact upon herring recruitment either directly or indirectly. Furthermore, when environmental conditions favour high jellyfish abundance, the possible impact by jellyfish on herring may increase. This study describes an exploration of correlative associations and coupled trends that suggest possible links between herring and jellyfish and the climate as encapsulated by the NAOI. There is a growing acceptance that fishery management needs to progress from single-species models to a more holistic ecosystem approach (Pikitch et al. 2004), and this study could be a contribution towards that goal.

\section{METHODS}

Jellyfish abundance. Medusa abundance data were collected over 15 yr (1971 to 1986, excluding 1984) during the routine summer International Council for the Exploration of the Sea (ICES) International 0-group Gadoid Surveys of the North Sea (Hay et al. 1990). Jellyfish were a bycatch of these surveys. Surveys were conducted using the International Young Gadoid Pelagic Trawl (IYGPT), and medusae of a broad range of diameters (1 to $47 \mathrm{~cm}$ ) were caught in the samples. The IYGPT had mesh sizes of $100 \mathrm{~mm}$ in wing, bosom and belly, tapering through intermediate mesh size to $10 \mathrm{~mm}$ knotless mesh in the extension piece and codend. The mouth opening of the net was approx. $14 \mathrm{~m}^{2}$. When fished at a maximum speed of 2.5 knots for $1 \mathrm{~h}$, about $65000 \mathrm{~m}^{3}$ of water was filtered, assuming $100 \%$ filtration efficiency (Hay et al. 1990). The sampling efficiency was internally consistent, and catch data are therefore directly comparable between years. Trawls were conducted during June and July every year. In 1971 and 1972 hauls were also made in August. From 2030 IYGPT trawls more than 430000 medusae were caught, identified and measured. Full survey methods are given in Hay et al. (1990) and Lynam et al. (2004). Only regions of the North Sea that were sampled in more than one year were included in analyses here (Fig. 1), and all abundance values were calculated from the raw data collected by, but not reported in, Hay et al. (1990). Jellyfish medusae were sampled throughout the Buchan and Orkney/Shetland areas. In the Central region, however, an area east of

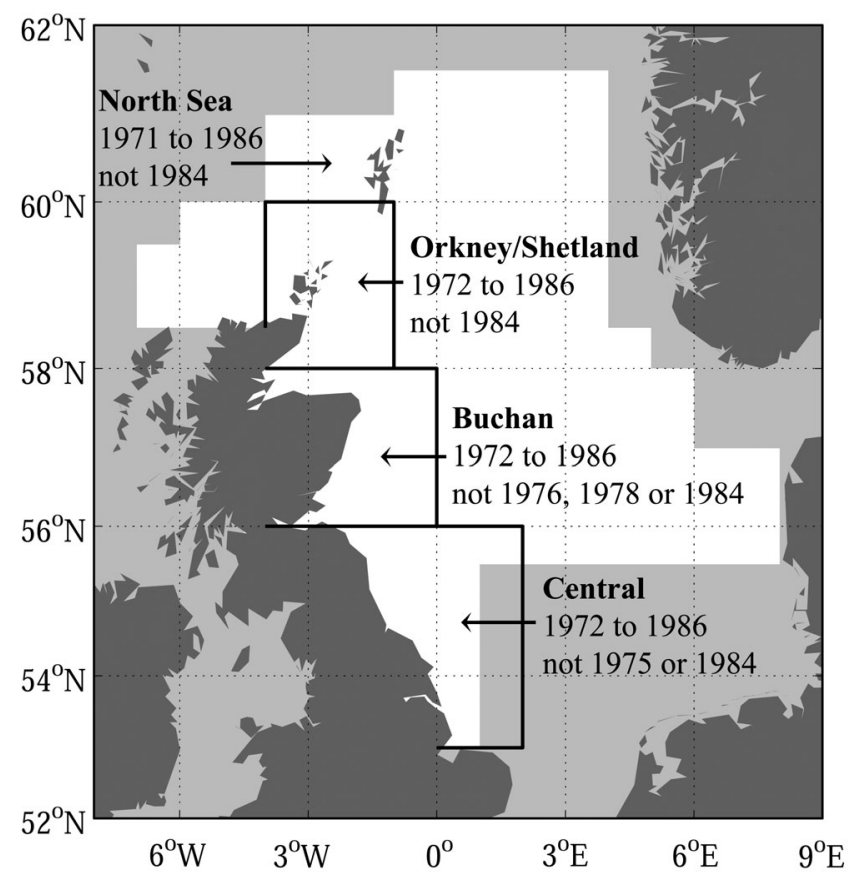

Fig. 1. North Sea regions where herring larvae (boxes, ICES) and medusae (white area) were sampled over more than $1 \mathrm{yr}$. Dates give years in which data were available for correlations. Dotted grid shows $3 \times 2^{\circ}$ squares

the spawning bank between 53 and $55.5^{\circ} \mathrm{N}$ and from 1 to $2^{\circ} \mathrm{E}$ was not sampled.

Analyses were conducted using maximum and median measures of medusa abundance. In temperate waters jellyfish exhibit a seasonal surge in numerical abundance that usually peaks in summer after phytoplankton and zooplankton blooms (i.e. during the IYGPT survey months). This peak, quantified by the maximum abundance of medusae, serves as a good indicator of interannual variability in jellyfish abundance in the North Sea. The median is a useful additional measure, particularly for Cyanea capillata, which does not form dense aggregations in the same manner as Aurelia aurita (Purcell 2003). The great patchiness in jellyfish distribution renders the sample mean an inadequate maximum-likelihood estimator of abundance.

Herring larval abundance. We used the herring Larval Abundance Index (LAI) (Rohlf \& Gröger 2003), which provides the mean number of larvae per ICES rectangle in the Buchan, Central and Orkney/Shetland areas (Heath 1993). This index arises from the ICES International Herring Larvae Surveys, which caught herring larvae $<10 \mathrm{~mm}$ long using a Gulf III 'standard sampler' $(260 \mu \mathrm{m}$ nylon mesh and a $20 \mathrm{~cm}$ mouth aperture). These standard surveys operated a double oblique haul from the surface to within $5 \mathrm{~m}$ of the seabed and back, with a vertical ascent rate of approx. 
$5 \mathrm{~m} \mathrm{~min}^{-1}$. The volume of water filtered by the net was measured with a calibrated flowmeter mounted in the centre of the mouth opening of the nose cone. Herring larvae, aged between 10 and $15 \mathrm{~d}$, were caught between 1 and 15 September 1972 to 1987, and these larvae were most likely spawned in mid-August (Heath 1993), when medusae are abundant (Russell 1970). For the Orkney/Shetland area, the LAI time series is complete throughout the jellyfish survey period. However, herring were not sampled in the Buchan region in 1976 or 1978, and the Central North Sea was not sampled in 1975.

Herring 0-group recruitment and stock biomass data. Recruitment, spawning stock and total stock biomass data for autumn-spawning herring are published by ICES for the North Sea, Eastern English Channel, Skagerrak and Kattegat combined (ICES 2003, 2004). Herring are assigned to the 0-group if they have no winter growth ring in their otoliths. Larvae do not gain a ring in their first winter, such that herring hatched in the autumn, say, of 1970 would metamorphose in spring/summer 1971 and would be referred to as 0-group throughout the year until they recruited to the 1-group on 1 January 1972 (Heath et al. 1997). Although the recruitment value is an estimate of 0 -group recruitment for 1 January in the year following the autumn hatching, the year class refers to the year of hatching. The Multiplicative Larval Abundance Index (MLAI) is used for tuning the ICES integrated-catch-at-age (ICA) model and, thus, the estimate of spawning stock biomass (SSB), but not the models of recruitment. Therefore, the regional LAIs presented here, in addition to the Downs LAI, are used indirectly to tune ICA and the SSB estimate. However, due to the great influence of the adult catch data and the convergence features of the ICA model, the ICA is relatively insensitive to the MLAI $(\mathrm{H}$. Sparholt pers. comm. 2004). The regional LAIs can therefore be considered independently of both SSB and 0-group recruitment.

Ricker modelling of herring survival to Age 0. We used a Ricker model (Eq. 1) to account for any variation in herring recruitment due to long-term population change (Gurney \& Nisbet 1998). This model predicts recruitment from the spawning stock biomass (SSB, tonnes):

$$
R_{\text {Ricker }}=(\mathrm{a} \cdot \mathrm{SSB}) \cdot \exp (-\mathrm{b} \cdot \mathrm{SSB})
$$

where $R_{\text {Ricker }}=$ recruits (millions) to 0-group (aged up to $17 \mathrm{mo}$ ) for year class $y$. The constants $\mathrm{a}=1.16 \times 10^{-1}$ and $\mathrm{b}=8.53 \times 10^{-7}$ were fitted by non-linear leastsquares estimation using the Gauss-Newton algorithm in R, V. 1.8.1 (R Development Core Team 2003).

The relative survival index $(S)$ of herring to approximately Age 0 can be calculated from the difference between the natural logarithms of the SSB and 0-group recruitment level $(R)$ :

$$
S=\ln (R)-\ln (\mathrm{SSB})
$$

where the units of survival are the logged number of recruits per tonne of spawning stock. Substitution of either the observed or Ricker-modelled estimate of recruitment for $\mathrm{R}$ in Eq. (2) provides a measure of the observed or expected larval survival respectively. The difference between the observed and the expected survival, the residual survival, is a dimensionless measure of external impacts (such as the climate or jellyfish) on larval survival:

$$
S_{\text {residual }}=S_{\text {observed }}-S_{\text {expected }}
$$

Climate. The winter (December to March) NAOI of the normalised sea level pressure difference between Lisbon, Portugal and Stykkisholmur/Reykjavik, Iceland was obtained from the National Center for Atmospheric Research, Climate and Global Dynamics Division, Boulder, Colorado, USA (Hurrell et al. 2003).

Analysis of jellyfish, NAOI, and herring relationships. Long-term trends: In data with non-zero temporal trends, Pearson correlations were made to assess whether or not trends were similar between pairwise combinations of time series. Correlations were conducted in SigmaPlot 2001 for Windows, and correlation significance, normality and homogeneity of variances were assessed at the 0.05 level using a Student's $t$-test.

Interannual variability: Prior to use in statistical analysis of interannual variability, medusa abundance, herring survival and recruitment, the LAI and NAOI were assessed for linear and polynomial temporal trends by taking least-squares fits against time, and were corrected where necessary. The significance of temporal trends was judged at the 0.05 level with a standard Student's $t$-test of the estimated slope parameter.

Multiple linear regressions of medusa abundance and the NAOI against survival, recruitment or LAI were made to compute models of the form:

$$
y_{t}=\beta_{0}+\beta_{1} \cdot x_{1 t}+\beta_{2} \cdot x_{2 t}+\beta_{3} \cdot x_{3 t}+\beta_{4} \cdot x_{2 t} \cdot x_{3 t}+e_{t}
$$

where $y_{t}$ is the residual survival, recruitment or LAI for year class $t, x_{1 t}$ is the abundance of medusae in year $t$, $x_{2 t}$ and $x_{3 t}$ are either the NAOI or the abundance of another jellyfish species or set to zero, $x_{2 t} \cdot x_{3 t}$ is the interaction term, $e_{t}$ is an error term with unit variance and zero mean, $\beta_{0}$ is the intercept; and $\beta_{1}, \beta_{2}, \beta_{3}$ and $\beta_{4}$ are the slope parameters estimated using linear regression. Natural logarithm transforms were used where necessary to normalise the distribution of residuals from linear correlations and regressions. Parameter significance for all models was assessed at the 
0.05 level using a Student's $t$-test. The model assumptions (linearity, homogeneity of variance, normality and independence of residuals) were tested following procedures outlined in Krzanowski (1998). Correlations between variables, linear regressions without interactions, and tests for normality and homogeneity of variances were conducted in SigmaPlot 2001 for Windows. Regressions with interactions were calculated and assessed in R (2003) using the Shapiro-Wilk normality test, the Breusch-Godfrey test for serial correlation, and plots of residuals against order and model values to test independence and variance homogeneity respectively. The significance level for each test was chosen to minimise corresponding Type II error (Krzanowski 1998).

\section{RESULTS}

\section{Long-term trends}

Temporal trends. Significant positive linear temporal trends $(p<0.05)$ were found in North Sea herring recruitment (observed data), SSB and residual survival in the North Sea as a whole. Positive trends were also found in the Orkney/Shetland region in the abundance of herring larvae and $\ln ($ median) abundance of Cyanea capillata. Significant quadratic trends (decreasing then increasing) were also found in herring total stock biomass and in C. capillata $\ln$ (maximum) abundance in the North Sea. In contrast, a significant negative trend was found in the Ricker-modelled survival of herring. All temporal trends were removed from the data in order to investigate relationships in interannual variability.

Herring larval abundance and jellyfish abundance in herring spawning areas. In the Orkney/Shetland region only, a long-term increasing trend was found in the herring larval abundance index (LAI). This correlated positively ( $\mathrm{p}<0.01, \mathrm{n}=14$ ) with the long-term trend in Cyanea capillata median abundance there $(\mathrm{r}=0.83)$.

Herring stock biomass and jellyfish abundance in the North Sea. The raw time series of herring total stock biomass (TSB) for the period 1971 to 1986 positively correlated with the median abundance of Cyanea capillata in the North Sea $(\mathrm{r}=0.80, \mathrm{p}<0.01$, $\mathrm{n}=15)$. The raw herring SSB correlated negatively with the $\ln$ (maximum) abundance of $A$. aurita $(r=$ $-0.75, \mathrm{p}<0.01, \mathrm{n}=15$, Fig. 2). Although the herring SSB did not significantly correlate with the maximum abundance of $C$. capillata, a significant positive correlation was found with median abundance $(\mathrm{r}=0.86, \mathrm{p}<$ $0.01, \mathrm{n}=15$ ). The maximum abundance of Aurelia aurita did not correlate with the median abundance of
C. capillata. The negative relationship between herring SSB and $A$. aurita abundance suggests that herring are in competition for prey with A. aurita. Herring SSB was also significantly positively correlated with the recruitment of herring $(\mathrm{r}=0.89, \mathrm{p}<0.01, \mathrm{n}=16$, Fig. 2), so much of the long-term variability in herring recruitment is due to changing adult abundance; this must be accounted for when exploring the effect of medusae on herring survival. The long-term change (between 1971 and 1986) in recruitment due to SSB variability was successfully captured by the Ricker model (Eq. 1); the Pearson correlation coefficient between observed and modelled recruitment was $\mathrm{r}=$ $0.89, \mathrm{p}<0.01, \mathrm{n}=16$. The Ricker-modelled survival of herring, i.e. survival expected on the basis of SSB and modelled recruitment, correlated positively with the $\ln$ (maximum) abundance of $A$. aurita throughout the North Sea $(\mathrm{r}=0.75, \mathrm{p}<0.01, \mathrm{n}=15)$, suggesting that $A$. aurita were abundant in years when high larval survival should have been attained. However, to explore whether or not $A$. aurita might have had an impact on

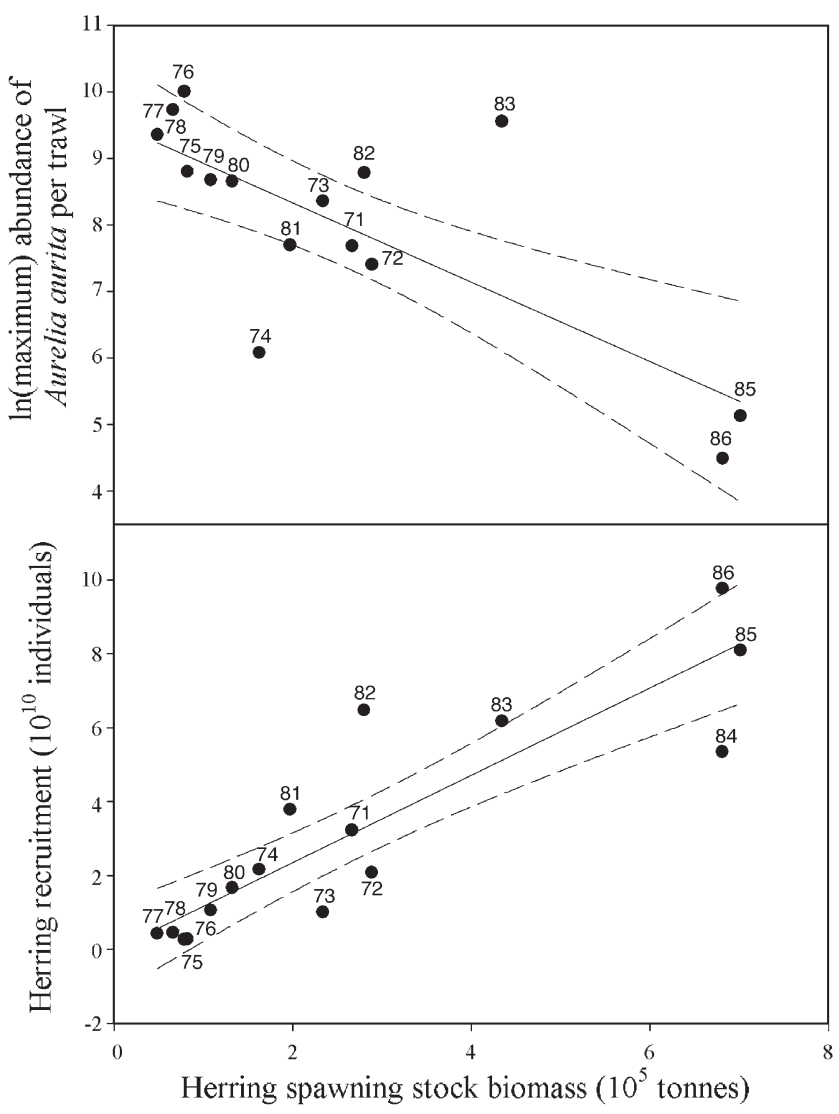

Fig. 2. Clupea harengus and Aurelia aurita in the North Sea. Correlations between the raw herring SSB (spawning stock biomass) and recruitment ( $\mathrm{r}=0.89, \mathrm{p}<0.01$, bottom panel) and between SSB and the $\ln$ (maximum) abundance of A. aurita $(\mathrm{r}=0.75, \mathrm{p}<0.01$, top panel) 
the survival of herring, the interannual variability in the residual survival (observed minus modelled) of herring had to be examined.

\section{Interannual variability}

Herring larval abundance and jellyfish abundance in spawning areas. Significant positive correlations were found between the herring larval abundance index (LAI) and the maximum abundance of Aurelia aurita in the Buchan $(\mathrm{r}=0.66, \mathrm{p}=0.04, \mathrm{n}=10$, Fig. 3$)$ and Central $(r=0.78, p=0.02, n=8)$ regions. In the Orkney/Shetland region, the detrended herring larval abundance correlated with the detrended $\ln$ (median) abundance of Cyanea capillata $(\mathrm{r}=0.69, \mathrm{p}<0.01$, $\mathrm{n}=14$ ).

Herring 0-group recruitment, herring stock biomass, and North Sea jellyfish abundance. A significant positive relationship was found between the detrended herring recruitment time series for the period 1971 to 1986 and the detrended herring spawning stock biomass $(\mathrm{r}=0.79, \mathrm{p}<0.01, \mathrm{n}=16$, Fig. 4). The maximum abundance of Aurelia aurita also correlated significantly with recruitment $(A$. aurita $\mathrm{r}=-0.60, \mathrm{p}=0.02, \mathrm{n}=15$ ). Significant negative correlations were also found between herring SSB and both the $\ln$ (maximum) A. aurita abundance and the detrended time series of Cyanea capillata abundance (A. aurita $\mathrm{r}=-0.67, \mathrm{p}<0.01, \mathrm{n}=15$, C. capillata $\mathrm{r}=-0.68, \mathrm{p}<0.01, \mathrm{n}=15$, Fig. 4 ).

Herring survival and jellyfish abundance - possible impact by Aurelia aurita on herring survival. To determine whether or not changing jellyfish abundance was a significant factor in the recruitment of herring, the com-

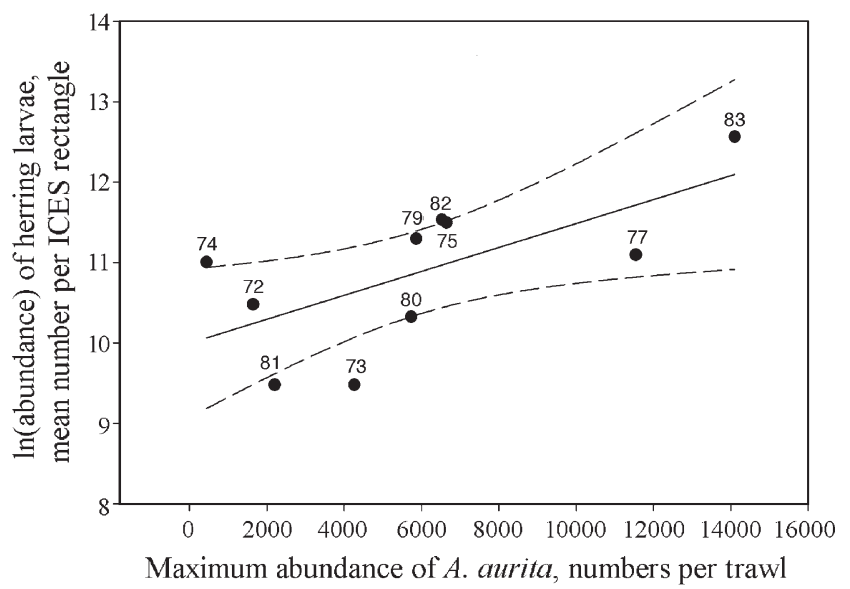

Fig. 3. Clupea harengus and Aurelia aurita. Relationship between abundances at the Buchan spawning ground $(\mathrm{r}=0.66$, $\mathrm{p}=0.04$ ) with $95 \%$ confidence interval (dashed lines). Herring larval abundances are mean numbers per ICES triangle and jellyfish abundance are maximum numbers per trawl

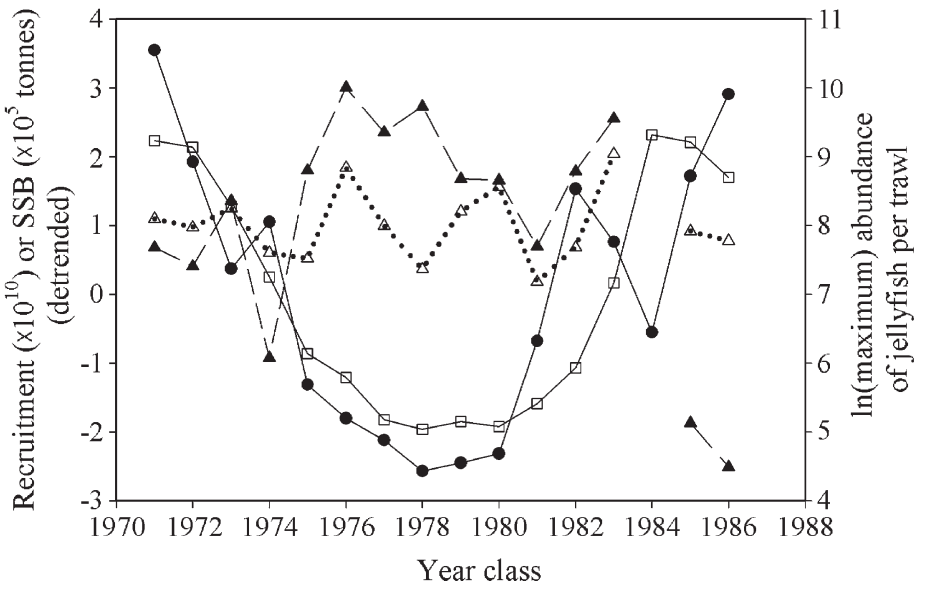

Fig. 4. Clupea harengus, Aurelia aurita and Cyanea capillata in the North Sea. Detrended time series of herring recruitment (solid line, $\bullet$ ), SSB (solid line, $\square$ ) and the abundance of $A$. aurita (dashed line, $\mathbf{\Delta}$ ) and $C$. capillata (dotted line, $\Delta$ ). For ease of comparison, the $C$. lamarckii data are all +5 . Correlation coefficient between herring recruitment and SSB, $\mathrm{r}=$ 0.79 ; between herring recruitment and medusa abundances:

A. aurita $\mathrm{r}=-0.67$ and C. capillata $\mathrm{r}=-0.68($ all $\mathrm{p}<0.01)$

ponent of variability in survival due to the environment (i.e. residual survival) was correlated against the abundance of each jellyfish species. A significant negative relationship was found between detrended residual survival and maximum Aurelia aurita abundance $(\mathrm{r}=$ $-0.61, \mathrm{p}=0.02, \mathrm{n}=15$, Fig. 5), suggesting that $A$. aurita may be detrimental to the survival of herring larvae.

Climatic modulation of possible jellyfish impact on survival. Further multiple regression analyses were conducted to explore the role of climate change in mediating the possible impact of jellyfish on herring survival and recruitment. The detrended herring re-

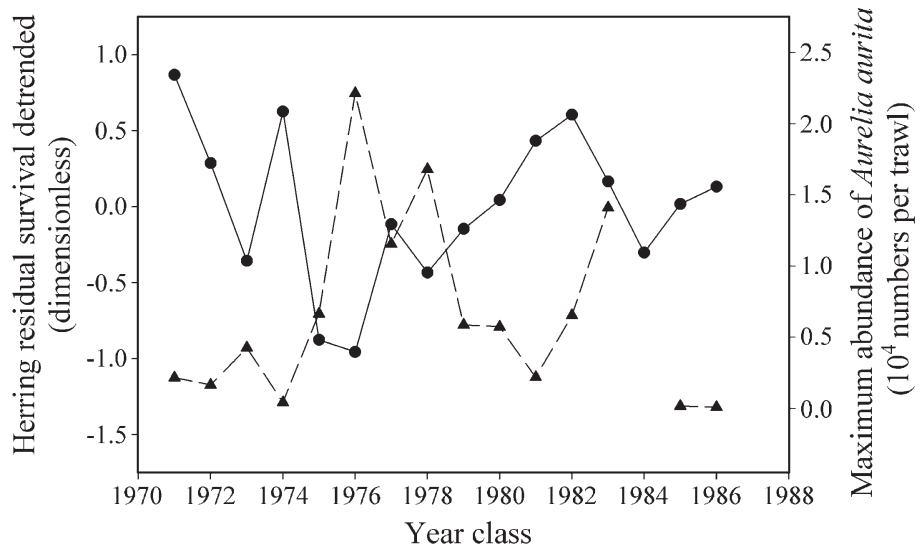

Fig. 5. Clupea harengus and Aurelia aurita time series. Relationship between abundance of $A$. aurita (dashed line, triangle) in the North Sea and larval herring residual survival (solid line, circle) $(r=-0.61, p=0.02)$ 
sidual survival and recruitment were regressed against medusa abundance with the NAOI as an additional explanatory variable. Maximum abundance of Aurelia aurita was included in the model since it was the only measure that correlated with herring residual survival in addition to the LAI in the Buchan and Central regions. Cyanea capillata was also included because the $\ln$ (abundance) of this medusa was correlated significantly with the LAI in the Orkney/Shetland region.

An initial model of herring residual survival without interactions between the 3 explanatory variables suggested that the abundance of Cyanea capillata and the NAOI were not significant variables. However, changes in the NAO could result in shifts in the relative distributions of the jellyfish species, so interactions between the explanatory variables were explored. Although there was no significant interaction between the NAOI and the abundance of Aurelia aurita, a significant interaction between the abundance of C. capillata and the NAOI was found when the interaction was included as an additional explanatory variable with the abundances of $A$. aurita and $C$. capillata and with the NAOI; the proportion of variability explained increased by $25 \%$ over the model with $A$. aurita alone. The detrended residual survival and the observed recruitment were modelled using Eq. (4) with $x_{1}=$ maximum abundance of $A$. aurita, $x_{2}=\ln$ (maximum) abundance of C. capillata, $x_{3}=$ NAOI and an interaction between $x_{2}$ and $x_{3}$. The model yielded the following results: for $y=$ detrended herring residual survival $\mathrm{r}^{2}=$ $0.62, \mathrm{p}=0.03, \mathrm{n}=15$; for $y=$ detrended recruitment $\mathrm{r}^{2}=$ $0.78, \mathrm{p}<0.01, \mathrm{n}=15$ (Fig. 6 \& Table 1). The same model also fit significantly to the detrended recruitment, but not residual survival, with $\ln$ (maximum) substituted for maximum $A$. aurita $\left(\mathrm{r}^{2}=0.82, \mathrm{p}<0.01, \mathrm{n}=\right.$ 15). In each model all variables were significant at the 0.05 level, with the exception of the abundance of $C$. capillata in the model of herring survival, which suggests that this medusa might not directly influence survival but may indirectly affect recruitment of herring (Table 1).

No significant relationship was found between the NAOI and either the residual survival or recruitment of herring or the abundance of any medusa in the full North Sea dataset. Therefore, the inclusion of the NAOI as an additional explanatory variable in the linear model (Eq. 4) does not violate the assumption of independent variables. Herring survival was indeed correlated with the abundance of Aurelia aurita, as was herring recruitment; however, herring survival does not influence $A$. aurita abundance. A. aurita medusae are abundant in advance of, and during, the spawning and hatching season. Therefore, A. aurita is a predictor of herring survival, and not the reverse, and the assumption of independence is upheld.
Modelled herring residual survival (dimensionless) A. aurita $+\ln (C$. capillata $)+\mathrm{NAOI}+[\ln (C$. capillata $) \times \mathrm{NAOI}]$

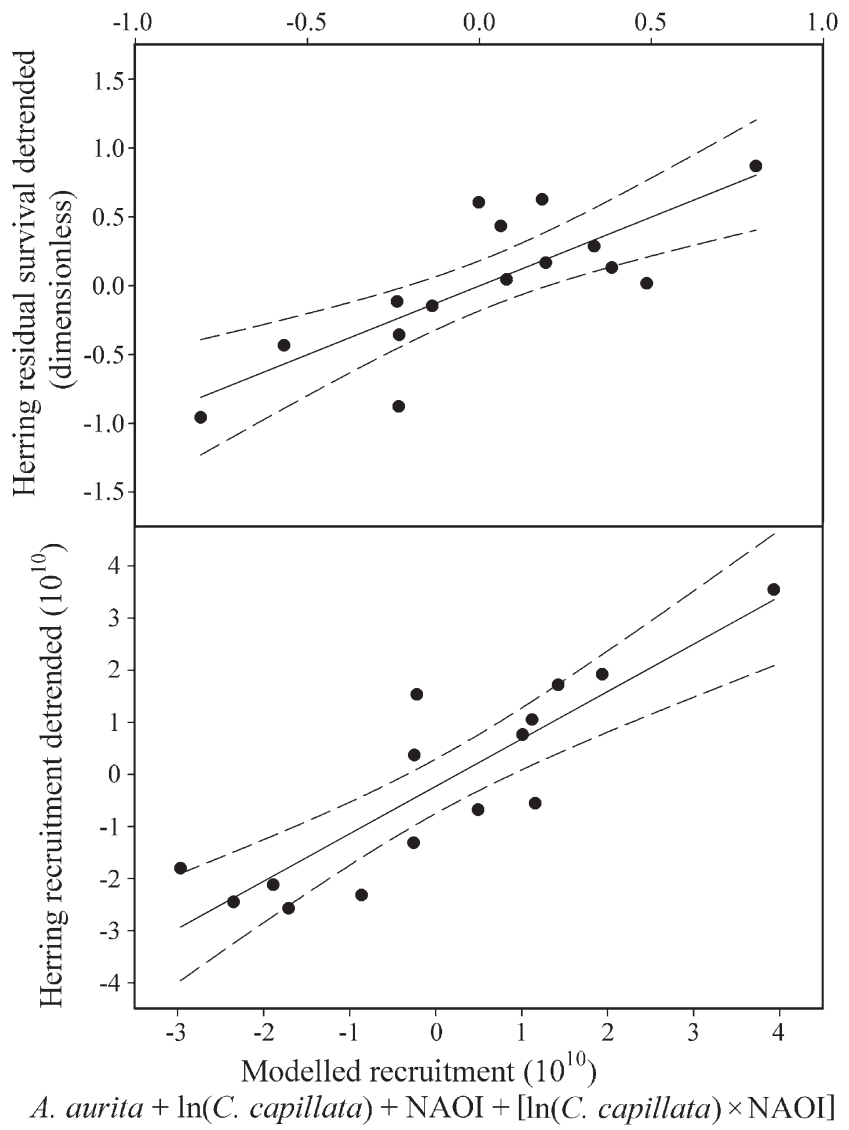

Fig. 6. Clupea harengus, Aurelia aurita and Cyanea capillata. Climatic modulation of jellyfish impacts on herring. Linear regression model (solid line with dashed lines for the 95\% confidence interval) with the maximum abundance of $A$. aurita $\left(x_{1}\right), \ln$ (maximum) abundance of $C$. capillata $\left(x_{2}\right)$ and the NAOI $\left(x_{3}\right)$ with an NAOI-C. capillata interaction $\left(x_{2} \cdot x_{3}\right)$ as explanatory variables vs. herring residual survival $\left(y_{\mathrm{S}}\right)$ detrended (top, $\mathrm{r}^{2}=0.62, \mathrm{p}=0.03, y_{\mathrm{S}}=91.97-5.95 \times 10^{-5} \mathrm{x}_{1}-$ $\left.8.76 \times 10^{-2} x_{2}-1.91 x_{3}+0.201 x_{2} \cdot x_{3}\right)$ and vs. herring 0 -group recruitment $\left(y_{\mathrm{R}}\right)$ detrended (bottom, $\mathrm{r}^{2}=0.78, \mathrm{p}<0.01$, $y_{\mathrm{R}}=8.19 \times 10^{4}-1.78 x_{1}-1.29 \times 10^{4} x_{2}-4.95 \times 10^{4} x_{3}+8.91 \times$ $\left.10^{3} x_{2} \cdot x_{3}\right)$

\section{DISCUSSION}

Medusae may exert top-down control over marine ecosystems (Schneider \& Behrends 1998, Oguz et al. 2001), and previous studies have suggested that jellyfish may impact on herring larval survival directly and indirectly through predation on ichthyoplankton and zooplankton (Bailey 1984, Möller 1984, Purcell 2003). Whether or not these interactions between jellyfish and finfish have any measurable long-term impact on populations of either is as yet unknown, but it has been suggested that the overexploitation of fish stocks could increase prey availability and release jellyfish from 
Table 1. Regression model results (with the proportion of variability explained by the model $\mathrm{r}^{2}$ and significance value $\mathrm{p}$ ) for North Sea herring Clupea harengus recruitment $(y, A, B)$ and residual survival $(y, C)$ against the maximum abundances of Aurelia aurita $\left(x_{1}\right)$ and Cyanea capillata $\left(x_{2}\right)$ and the NAOI $\left(x_{3}\right)$ with an interaction $\left(x_{2} \cdot x_{3}\right)$ between the NAOI and C. capillata for the period 1971 to 1986 (excluding 1984). Estimated and standardised $\beta$ values are shown with $t$-statistics and probabilities that the statistics are not significantly different from zero. NAOI: North Atlantic Oscillation Index. Note ln transformations of C. capillata data and A. aurita data in (A) only

\begin{tabular}{|c|c|c|c|c|}
\hline Explanatory variable & $\beta_{\text {estimated }}$ & $\beta_{\text {standardised }}$ & $t$-statistic & $\mathrm{p}$ \\
\hline \multicolumn{5}{|c|}{ (A) Response $y=$ herring recruitment $\left(\mathrm{r}^{2}=0.82, \mathrm{p}<0.01\right)$} \\
\hline Intercept & $1.30 \times 10^{5}$ & - & 6.16 & $<0.001$ \\
\hline$x_{1}=\ln ($ Aurelia aurita $)$ & $-6.96 \times 10^{3}$ & -0.557 & -3.59 & 0.005 \\
\hline$x_{2}=\ln ($ Cyanea capillata $)$ & $-1.37 \times 10^{4}$ & -0.565 & -3.39 & 0.007 \\
\hline$x_{3}=$ NAOI & $-4.31 \times 10^{4}$ & -3.330 & -3.41 & 0.007 \\
\hline$x_{2} \cdot x_{3}=\ln ($ Cyanea capillata $) \times$ NAOI & $7.81 \times 10^{3}$ & 3.621 & 3.67 & 0.004 \\
\hline \multicolumn{5}{|c|}{ (B) Response $y=$ herring recruitment $\left(\mathrm{r}^{2}=0.78, \mathrm{p}<0.01\right)$} \\
\hline Intercept & $8.19 \times 10^{4}$ & - & 3.47 & 0.006 \\
\hline$x_{1}=$ Aurelia aurita & -1.78 & -0.572 & -3.06 & 0.012 \\
\hline$x_{2}=\ln ($ Cyanea capillata $)$ & $-1.29 \times 10^{4}$ & -0.532 & -2.81 & 0.019 \\
\hline$x_{3}=$ NAOI & $-4.95 \times 10^{4}$ & -3.827 & -3.53 & 0.005 \\
\hline$x_{2} \cdot x_{3}=\ln ($ Cyanea capillata $) \times$ NAOI & $8.91 \times 10^{3}$ & 4.133 & 3.77 & 0.004 \\
\hline \multicolumn{5}{|c|}{ (C) Response $y=$ herring residual survival $\left(r^{2}=0.62, p=0.03\right)$} \\
\hline Intercept & 91.97 & - & 1.15 & 0.276 \\
\hline$x_{1}=$ Aurelia aurita & $-5.95 \times 10^{-5}$ & -0.753 & -3.03 & 0.013 \\
\hline$x_{2}=\ln ($ Cyanea capillata $)$ & $-8.76 \times 10^{-2}$ & -0.142 & -0.57 & 0.584 \\
\hline$x_{3}=$ NAOI & -1.91 & -3.620 & -2.51 & 0.031 \\
\hline$x_{2} \cdot x_{3}=\ln ($ Cyanea capillata $) \times$ NAOI & 0.201 & 3.671 & 2.52 & 0.031 \\
\hline
\end{tabular}

competitively imposed restrictions on population abundance, which may exacerbate any detrimental effect (Pauly et al. 1998, 2002, Sommer et al. 2002).

This study is the first to quantify interactions between jellyfish abundance and herring recruitment over extended time periods, and to account for spawning stock biomass variation and climatic factors. However, correlative studies of this type describe associations and coupled trends that may or may not be causal. Therefore, the possible links between herring and jellyfish and the climate suggested here require further study to clarify the causal mechanism. We consider 4 possible underlying mechanisms for the correlations found between herring survival and jellyfish abundance here: (1) The abundances of Aurelia aurita and Cyanea capillata are high during the period of lowest herring SSB due to the release of jellyfish from competition with herring. Herring residual survival is thus lower than expected because at low herring stock and high jellyfish abundances the possible competition and predation impacts of jellyfish are greatest. (2) The correlations describe coupled trends that are a result of NAO-driven environmental change. (3) The association between herring and jellyfish is the result of more widespread changes in the North Sea ecosystem, e.g. plankton community change or the 'Gadoid Outburst', possibly due to the 'Great Salinity Anomaly'. (4) The relationships describe impacts by jellyfish (A. aurita and $C$. capillata) on herring that are mediated by
NAO-driven environmental change. These mechanisms are discussed in more detail in the following section.

\section{Mechanism 1: Increased competition and predation impacts by jellyfish on herring survival}

Whatever the cause in the declining herring stock during the 1960s and early 1970s (e.g. overfishing, climate change, pollution), the indirect effect may have been to increase the food available for jellyfish. The negative correlation between herring SSB and the abundance of Aurelia aurita between 1971 and 1986 suggests that as the herring stock decreased, so the medusa abundance increased, possibly through a release from competition with the herring stock (see Figs. 2 \& 4). The negative correlation between herring residual survival and $A$. aurita abundance suggests that the rise in $A$. aurita abundance may have caused further decreases in the survival of herring larvae irrespective of changes in the adult herring population (see Fig. 5).

The positive relationships between abundances of herring larvae and Aurelia aurita in the Buchan and Central areas, and Cyanea capillata in the Orkney/ Shetland area, suggests that both herring spawning success and jellyfish abundance show a similar response to interannual environmental change. Condi- 
tions that are favourable for a jellyfish 'bloom' (such as food availability and temperature) would also therefore appear to be beneficial for herring larval production. This increases the likelihood of interactions between jellyfish and herring. Predation by medusae on herring larvae, and direct competition between medusae and herring, may occur when they overlap spatially and temporally, and indirect competition may arise if a time lag exists. For instance, the herring stock considered here spawns during the late summer and autumn (August to September) when medusae are maturing; therefore, larvae spawned towards the end of the season may hatch after the principal period of jellyfish abundance. The main period of $A$. aurita and C. capillata medusa abundance in the North Sea is during the early summer (May to August), and by September/October these species become scarce in the plankton (Russell 1970). Medusae are therefore most likely to impact directly on herring via competition and predation during August in the spawning areas. Indirect impact via competitive removal of food by medusae during the summer might also result in low prey availability for herring hatchlings in the autumn, and thus poor larval survival (Olesen 1995). The early life stages of herring suffer highest mortality, so much so that the year-class strength is determined generally by the time young fish have passed larval and early metamorphosis stages. Thus the possible impact of medusae might occur in the critical period for herring (Axenrot \& Hansson 2003).

An illustration of this possible mechanism for the release of jellyfish from competition may be the 10-fold rise in Chrysaora melanaster abundance in the Bering Sea (1979 to 1999), which was negatively correlated $(r=-0.69, p<0.01)$ with the decreasing abundance of potentially competitive planktivorous forage fishes (juvenile herring Clupea pallasi, Age 1 pollock Theragra chalcogramma and capelin Mallotus villosus) (Brodeur et al. 2002). However, climate change and 'regime shift' may also have driven those trends (Brodeur et al. 1999).

\section{Mechanism 2: Coupled trends resulting from NAO-driven environmental change}

Climatic variation, as encapsulated by the NAOI, may influence the abundance and distribution of herring and jellyfish. Lynam et al. (2004) found that the abundance of Aurelia aurita medusae in regions in the eastern and western North Sea were significantly negatively related to the winter NAOI $\left(\mathrm{r}^{2}>0.50\right.$ and $\mathrm{p}<$ 0.01 for both regions). Lynam et al. (2005) extended the analysis and found that the abundance of A. aurita north of Scotland was positively correlated with the
NAOI $\left(r^{2}=0.40\right.$ and $\left.p<0.05\right)$, whereas east of Scotland, in a region approximately the same as the Buchan area, both $A$. aurita and Cyanea capillata were negatively correlated with the NAOI $\left(A\right.$. aurita $\mathrm{r}^{2}=0.47$ and $\mathrm{p}=0.01$, C. capillata $\mathrm{r}^{2}=0.51$ and $\mathrm{p}<0.01$ ).

Climate variation has been shown to govern alternating periods dominated by Norwegian springspawning herring and sardines Sardina pilchardus in the English Channel and off south-west England. A high NAOI has been associated with dominance by herring there, and, conversely, the Bohuslän herring periods in the Skagerrak appear to coincide with a low NAOI (Alheit \& Hagen 1997). The NAOI has also been found to be significantly positively correlated with the year-class strength of spring-spawning herring in the Baltic Sea $\left(r^{2}=0.35, p<0.03, n=10\right)$ and has been used to improve predictive models of herring recruitment from young-of-the-year densities (Axenrot \& Hansson 2003).

NAO variation may be the root cause of changes in both jellyfish abundance and the distribution of herring spawners and thus regional spawning success. Therefore, it could be argued that the correlations found here may merely be coupled trends rather than evidence for an impact by jellyfish on herring survival. However, the NAOI was not significantly correlated with either the herring residual survival or recruitment; therefore, if there is a link between NAO-related environmental change and residual survival, it is probably mediated by associated ecosystem changes such as changing zooplankton abundance.

\section{Mechanism 3: The 'Great Salinity Anomaly', plankton community change and the 'Gadoid Outburst'}

The gradual decline in the North Sea herring stocks during the 1950s and 1960s may have been caused principally by overfishing, but the eventual collapse of the stocks in 1977 may have been triggered by environmental change and low survival of herring larvae. The Great Salinity Anomaly of the 1970s saw a huge volume of cold, low-salinity water travel around the North Atlantic gyre from 1968 to 1981 and invade the North Sea during the low NAOI period 1977 to 1979 (Dickson et al. 1988, Belkin et al. 1998). In addition, changes in the plankton community contributed to the Gadoid Outburst of the 1970s, which saw a dramatic rise in the abundance of gadoids in the North Sea (Hislop 1996, Beaugrand et al. 2003).

Although the Buchan herring stock initially increased, overall the North Sea herring did not follow the rise in gadoid abundance (Rothschild 1998). The subsequent long-term decreasing trend in the herring 
stock appeared to follow a decline in zooplankton abundance, which in turn would presumably increase competition between herring and other planktivores, including jellyfish (Aebischer et al. 1990, Rothschild 1998). Therefore, it is possible that the correlations described here are incidental associations resulting from a period of extensive change in the North Sea. Further research is necessary to determine whether or not the links proposed here between jellyfish and herring recruitment have persisted to the present. If so, then the specific changes resulting from the Great Salinity Anomaly were not the causative factor for the coupled trends observed here.

\section{Mechanism 4: NAO-mediated possible impact by jellyfish on herring survival}

We have suggested that the positive correlations between jellyfish abundance and the larval abundance index (LAI) indicate that both the spawning success of herring and the regional abundance of jellyfish respond similarly to environmental change. Therefore, as important predators of zooplankton, jellyfish could form an intermediary between NAO-driven environmental change and herring residual survival. We explored the role that jellyfish and the NAO may play in driving the interannual variability in herring residual survival and recruitment through multivariate regression analyses.

Both herring survival and recruitment were regressed against the abundances of Aurelia aurita and Cyanea capillata with an NAOI interaction (see Fig. 6, Eq. 4 \& Table 1). The interaction term suggests either that jellyfish form an intermediary, linking climatic change to herring survival (see Fig. 7 , right panel), or that climatic changes mediate the possible impact of medusae on herring (see Fig. 7, left \& centre panels). When either herring residual survival or recruitment was regressed (without interactions) against the 3 explanatory variables, only the abundance of $A$. aurita appeared significant. This suggests that the interannual change in herring survival is linked primarily to the abundance of $A$. aurita. Once an interaction was included between the abundance of $C$. capillata and the NAOI, both variables appeared to have a significant role. C. capillata is a predator on the smaller $A$. aurita and may regulate the abundance of $A$. aurita (Båmstedt et al. 1997). In addition, the NAO may drive environmental changes that alter the spawning success of herring and the relative abundance of the jellyfish species $A$. aurita and $C$. capillata (see Mechanism 2). Thus, both $C$. capillata and the NAO may mediate the possible impact of $A$. aurita on herring survival.

In these regression models (with interactions) of herring survival and recruitment (see Eq. 4 \& Table 1), the coefficient of the Aurelia aurita variable $\left(\beta_{1}\right)$ is negative, suggesting that as the abundance of $A$. aurita medusae increases, the survival of herring decreases. C. capillata interacts with the NAOI (the C. capillata coefficient $\beta_{2}$ and the NAOI $\beta_{3}$ are negative, whereas the interactions $\beta_{4}$ are positive) so that constant NAO (or C. capillata) conditions must be considered in order to understand the possible impact of C. capillata (or the NAO) on herring.

For a high NAO, as the abundance of Cyanea capillata increases, the survival of herring also increases

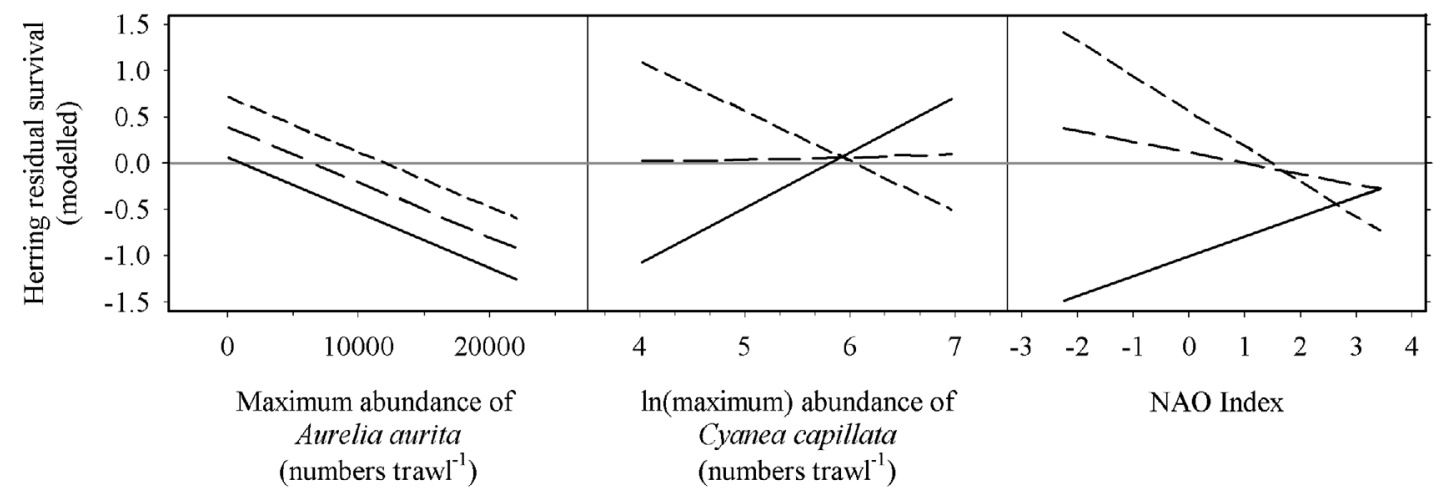

Fig. 7. Clupea harengus, Aurelia aurita and Cyanea capillata. The modelled effect on herring residual survival $\left(y_{\mathrm{S}}=91.97-5.95 \times\right.$ $\left.10^{-5} x_{1}-8.76 \times 10^{-2} x_{2}-1.91 x_{3}+0.201 x_{2} \cdot x_{3}\right)$ of changes in the NAO and jellyfish abundance over the observed ranges of the NAOI $\left(x_{3}\right)$ and the maximum medusa abundance in the period 1971 to 1986. Left panel: change in expected survival due to variation in $A$. aurita abundance $\left(x_{1}\right)$ at a constant median abundance of $C$. capillata $\left(x_{2}=209\right.$ medusae); centre panel: varying C. capillata abundance $\left(x_{2}\right)$ at median $A$. aurita abundance $\left(x_{1}=5736\right.$ medusae), where in both left and centre panels the solid lines represent high NAOI $\left(x_{3}=3.42\right)$, long-dashed lines median NAOI $\left(x_{3}=0.56\right)$ and short-dashed lines low NAOI $\left(x_{3}=-2.25\right)$; right panel: effect on survival due to changing NAO conditions under fixed medusa abundance, where solid lines represent highest abundance of medusae $\left(x_{1}=22125\right.$ A. aurita and $x_{2}=1064$ C. capillata $)$; long-dashed lines median values $\left(x_{1}=5736\right.$ A. aurita and $x_{2}=209$ C. capillata) and short-dashed lines lowest medusa abundance $\left(x_{1}=89 \mathrm{~A}\right.$. aurita and $x_{2}=56$ C. capillata) 
(see Fig. 7, centre panel, solid line). In contrast, under low NAO conditions, an increase in C. capillata abundance decreases survival (see Fig. 7, centre panel, short-dashed line). Similarly, fixing C. capillata abundance in the model can reveal the effect of NAO variation. For a high abundance of $C$. capillata, as the NAOI increases, the survival of herring increases (see Fig. 7, right panel, solid line), whereas with a low or median abundance of $C$. capillata an increase in the NAOI appears to be detrimental to herring survival (see Fig. 7, right panel, short-dashed line).

If both Aurelia aurita and Cyanea capillata are at very high abundance, herring larval survival is likely to be lower than expected, irrespective of the NAO phase, although it may be much worse at a low NAOI (see Fig. 7, right panel, solid line). However, if both jellyfish species are at median or low abundance, the herring residual survival is only likely to be lower than expected if the NAO is in a high phase (NAOI > approx. 1.5) (see Fig. 7, right panel, dashed lines). This suggests that a high NAO has a largely detrimental impact on the survival of autumn-spawning North Sea herring.

The possible negative effect of Aurelia aurita medusae on larval survival appears to be enhanced under low NAO conditions if, and only if, Cyanea capillata abundance is high (see Fig. 7, centre panel, short-dashed line). Lynam et al. (2005) found that A. aurita and $C$. capillata abundance in the Buchan spawning area is expected to be high during low NAO years. Therefore, the possible detrimental effect of jellyfish on larval survival may be altered most by the NAO there. When a high NAOI prevails, jellyfish are expected to be more abundant north of Scotland and west of the Orkneys (Lynam et al. 2005), and there is likely to be less spatial overlap between the medusae and herring larvae. During these high NAO years, an increase in the abundance of $C$. capillata is associated with a rise in herring survival, which again suggests that both $C$. capillata and herring survival benefit from similar conditions in the North Sea (see Fig. 7, centre panel, solid line). The apparent increase of the detrimental impact on herring residual survival under high NAO conditions, if the abundance of $C$. capillata is median to low (Fig. 7, left panel, solid line), therefore suggests that high NAO conditions result in an additional negative impact on herring that is independent of $A$. aurita. However, this NAO-driven impact appears to be much weaker than that expected by a high abundance of jellyfish under a low NAO (see Fig. 7, right panel).

The collapse of the herring stocks during the 1970s did not happen uniformly over the entire North Sea. As the whole North Sea population abundance declined, the distribution of spawning activity moved northwards until, during the minimum herring abundance and maximum Aurelia aurita abundance period 1976-1978, the population was concentrated at Shetland (Heath et al. 1997). Therefore, the herring stocks retreated to the area where Cyanea capillata was the most common medusa and the effect of the generally more abundant $A$. aurita was minimised. The herring stocks recovered following a ban on North Sea herring fishing between 1977 and 1981. This coincided with a return to the positive phase of the NAO in 1980 and, perhaps more importantly, a reduction in the abundance of $A$. aurita.

\section{CONCLUDING REMARKS}

The regional abundance of Aurelia aurita and Cyanea capillata medusae was generally greatest in years when highest abundances of herring larvae were found in the spawning areas of the Buchan, Central and Orkney/Shetland regions of the North Sea. Years of expected high larval survival of autumn-spawning herring coincided with an overall high abundance of A. aurita in the North Sea. However, there appears to be a significant negative impact of $A$. aurita on herring survival and recruitment in the North Sea, which might result through a combination of predation on herring larvae by medusae and competition between larvae and medusae for zooplankton food. Whether or not jellyfish contribute directly to declines in fish stocks or become more prominent in overexploited ecosystems is hard to discern, particularly as a reduction in herring stocks may release $A$. aurita and $C$. capillata from competition and exacerbate the possible impact of jellyfish on larval herring survival. We suggest that the interannual relationships between $A$. aurita abundance and herring residual survival is evidence for an impact by these common medusae on herring recruitment. This possible impact on herring appears to be climatically modulated via relative shifts in the distribution and abundance of the herring and medusa populations. If jellyfish are consistently abundant, a switch to a low NAOI might result in a greater impact by jellyfish on herring survival (Fig. 7, right panel, solid line). It is therefore important that jellyfish abundance in the North Sea be monitored and that herring recruitment assessed with respect to ecosystem change. Specifically, management of North Sea herring stocks might benefit from incorporation of predation and competition effects of medusae into forecasting models of herring recruitment.

Acknowledgements. We thank J. Hurrell for making the NAOI data freely available at http://www.cgd.ucar.edu/cas/ jhurrell/index.html. We are grateful to H. Sparholt (ICES Herring Assessment Working Group) for helpful discussions on 
herring recruitment and A. MacDonald and the anonymous reviewers for their helpful comments on earlier drafts of this paper. C.P.L. was funded by the Natural Environment Research Council, United Kingdom.

\section{LITERATURE CITED}

Aebischer NJ, Coulson JC, Colebrook JM (1990) Parallel long-term trends across 4 marine trophic levels and weather. Nature 347:753-755

Alheit J, Hagen E (1997) Long-term climate forcing of European herring and sardine populations. Fish Oceanogr 6:130-139

Axenrot T, Hansson S (2003) Predicting herring recruitment from young-of-the-year densities, spawning stock biomass, and climate. Limnol Oceanogr 48:1716-1720

Bailey KM (1984) Comparison of laboratory rates of predation on 5 species of marine fish larvae by 3 planktonic invertebrates-effects of larval size on vulnerability. Mar Biol 79: 303-309

Båmstedt UB, Ishii H, Martinussen MB (1997) Is the scyphomedusa Cyanea capillata (L.) dependent on gelatinous prey for its early development. Sarsia 82:269-273

Beaugrand G, Brander KM, Lindley JA, Souissi S, Reid PC (2003) Plankton effect on cod recruitment in the North Sea. Nature 426:661-664

Belkin IM, Levitus S, Antonov J, Malmberg SA (1998) 'Great Salinity Anomalies' in the North Atlantic. Prog Oceanogr 41: $1-68$

Brodeur RD, Mills CE, Overland JE, Walters GE, Schumacher JD (1999) Evidence for a substantial increase in gelatinous zooplankton in the Bering Sea, with possible links to climate change. Fish Oceanogr 8:296-306

Brodeur RD, Sugisaki H, Hunt GL (2002) Increases in jellyfish biomass in the Bering Sea:implications for the ecosystem. Mar Ecol Prog Ser 233:89-103

Dickson RR, Meincke J, Malmberg SA, Lee AJ (1988) The 'Great Salinity Anomaly' in the northern North Atlantic 1968-1982. Prog Oceanogr 20:103-151

Gurney WSC, Nisbet RM (1998) Ecological dynamics. Oxford University Press, New York

Hay SJ, Hislop JRG, Shanks AM (1990) North-Sea scyphomedusae-summer distribution, estimated biomass and significance particularly for O-group gadoid fish. Neth J Sea Res 25:113-130

Heath M (1993) An evaluation and review of the ICES herring larval surveys in the North Sea and adjacent waters. Bull Mar Sci 53:795-817

Heath M, Scott B, Bryant AD (1997) Modelling the growth of herring from 4 different stocks in the North Sea. J Sea Res 38:413-436

Hislop JRG (1996) Changes in North Sea gadoid stocks. ICES J Mar Sci 53:1146-1156

Hurrell JW, Kushnir Y, Ottersen G, Visbeck M (2003) An overview of the North Atlantic Oscillation. In: Hurrell JW, Kushnir Y, Ottersen G, Visbeck M (eds) The North Atlantic Oscillation: climatic significance and environmental impact. American Geophysical Union, Washington, DC, Vol 134, p 1-35

ICES (2003) Report of the ICES advisory committee on fish management 3.5.8: Herring in Subarea IV, Division VIId and Division IIIa (autumn spawners). Copenhagen

ICES (2004) Report of the herring assessment working group for the area south of $62^{\circ} \mathrm{N}$. ICES CM 2004/ACFM:18

Editorial responsibility: Jennifer Purcell (Contributing Editor), Anacortes, Washington, USA
Krzanowski WJ (1998) An introduction to statistical modelling. Arnold, London

Lynam CP, Hay SJ, Brierley AS (2004) Interannual variability in abundance of North Sea jellyfish and links to the North Atlantic Oscillation. Limnol Oceanogr 49:637-643

Lynam CP, Hay SJ, Brierley AS (2005) Jellyfish abundance and climatic variation:contrasting responses in oceanographically distinct regions of the North Sea, and possible implications for fisheries. J Mar Biol Assoc UK 85:435-450

Mills CE (2001) Jellyfish blooms: are populations increasing globally in response to changing ocean conditions? Hydrobiologia 451:55-68

Möller H (1984) Reduction of a larval herring population by jellyfish predator. Science 224:621-622

Oguz T, Ducklow HW, Purcell JE, Malanotte-Rizzoli P (2001) Modeling the response of top-down control exerted by gelatinous carnivores on the Black Sea pelagic food web. J Geophys Res Oceans 106:4543-4564

Olesen NJ (1995) Clearance potential of jellyfish Aurelia aurita, and predation impact on zooplankton in a shallow cove. Mar Ecol Prog Ser 124:63-72

Pauly D, Christensen V, Dalsgaard J, Froese R, Torres F (1998) Fishing down marine food webs. Science 279:860-863

Pauly D, Christensen V, Guenette S, Pitcher TJ, Sumaila UR, Walters CJ, Watson R, Zeller D (2002) Towards sustainability in world fisheries. Nature 418:689-695

Pikitch EK, Santora C, Babcock EA, Bakun A plus 13 others (2004) Ecosystem-based fishery management. Science 305: 346-347

Purcell JE (2003) Predation on zooplankton by large jellyfish, Aurelia labiata, Cyanea capillata and Aequorea aequorea, in Prince William Sound, Alaska. Mar Ecol Prog Ser 246: $137-152$

Purcell JE, Arai MN (2001) Interactions of pelagic cnidarians and ctenophores with fish:a review. Hydrobiologia 451: $27-44$

Purcell JE, Grover JJ (1990) Predation and food limitation as causes of mortality in larval herring larvae at a spawning ground in British Columbia. Mar Ecol Prog Ser 59:55-67

Purcell JE, Sturdevant MV (2001) Prey selection and dietary overlap among zooplanktivorous jellyfish and juvenile fishes in Prince William Sound, Alaska. Mar Ecol Prog Ser 210: 67-83

R Development Core Team (2003) R: A language and environment for statistical computing. R Foundation for Statistical Computing, Vienna

Rohlf N, Gröger J (2003) Report of the herring larvae surveys in the North Sea in 2002/2003. ICES, Copenhagen

Rothschild BJ (1998) Year class strengths of zooplankton in the North Sea and their relation to cod and herring abundance. J Plankton Res 20:1721-1741

Russell FS (1970) The medusae of the British Isles. II pelagic Scyphozoa with a supplement to the first volume on hydromedusae. Cambridge University Press, London

Schneider G, Behrends G (1998) Top-down control in a neritic plankton system by Aurelia aurita medusae-a summary. Ophelia 48:71-82

Sommer U, Stibor H, Katechakis A, Sommer F, Hansen T (2002) Pelagic food web configurations at different levels of nutrient richness and their implications for the ratio fish production: primary production. Hydrobiologia 484:11-20

Xian W, Kang B, Liu R (2005) Jellyfish blooms in the Yangtze estuary. Science 307:41

Submitted: July 6, 2004; Accepted: March 14, 2005

Proofs received from author(s): July 28, 2005 